\title{
The Effect of Plasmakinetic Cautery on Wound Healing and Complications in Mastectomy
}

\author{
Lutfi Dogan, Mehmet Ali Gulcelik, Murat Yuksel, Osman Uyar, Osman Erdogan, Erhan Reis \\ Department of General Surgery, Ankara Oncology Training and Education Hospital, Ankara, Turkey
}

\begin{abstract}
Purpose: Surgical equipment used in breast cancer surgery that affects wound healing and minimizes complications seems to be a popular investigation topic. The aim of this study is to evaluate the effect of plasmakinetic cautery on wound healing in patients receiving mastectomy. Methods: Forty-six consecutive breast cancer patients receiving modified radical mastectomy were evaluated prospectively. Plasmakinetic cautery was used in 24 operations and electrocautery was used in 22 operations in random order to manage skin flaps and excise breast tissue. In the postoperative period, vacuum drainage amount and duration time as well as the start time of arm exercises were recorded. Complications like seroma, surgical site infection, hematoma, and flap necrosis were determined. Results: Age, body mass index, breast volume and flap area parameters were similar in each group. Mean drainage duration was found to be 5.5 days in the plasmacautery group and 7.9 days in the electrocautery
\end{abstract}

group $(p=0.020)$. In the plasmacautery and electrocautery groups, mean drainage volume was 707 and $1,093 \mathrm{~mL}$, respectively $(p=0.025)$. There was no statistical significance between the groups when operation duration, amount of blood loss, time to start arm exercises, seroma, hematoma, surgical site infection, and flap necrosis were considered. Conclusion: Plasmakinetic cautery is a promising new surgical instrument that provides atraumatic, scalpel-like cutting precision and electrosurgical-like hemostasis, resulting in minimal tissue injury. So, plasmacautery shortens the drainage amount and duration time compared to electrocautery without elongating operation duration or increasing the amount of blood loss.

Key Words: Breast neoplasms, Complications, Plasmakinetic cautery, Wound healing

\section{INTRODUCTION}

Surgical equipment used in breast cancer surgery that affects wound healing and minimizes complications seems to be an investigation topic of interest these days. Although surgical blade and electrocautery are the most frequently used equipments, due to improvements in technology, new devices such as plasmakinetic cautery is beginning to play a role in breast surgery. An energy model derived from high grade radiofrequency and which ionizes the water vapor both in the air and in the tissue is the main working principle of plasmakinetic cautery. The aim of this study is to evaluate the effect of plasmacautery on wound healing and to assess advantages and/or restrictions as well as morbidity with use of this device

Correspondence to: Lutfi Dogan

Department of General Surgery, Ankara Oncology Training and Education Hospital, Mehmet Akif Ersoy mah. 13. Cad. NO:56. 06200 Demetevler, Ankara, Turkey

Tel: +90-312-3196209, Fax: +90-312-3454979

E-mail: lutfidogan1@yahoo.com

Received: January 2, 2013 Accepted: May 19, 2013 in patients receiving mastectomy.

\section{METHODS}

Between September and December 2011, 46 consecutive breast cancer patients receiving modified radical mastectomy were evaluated prospectively. The study was approved by the local ethics committee at Ankara Oncology Education and Research Hospital, Ankara, Turkey (IRB No: B18-12). Informed consent forms were obtained from all patients. Plasmakinetic cautery (PEAK Surgical Inc., Palo Alto, USA; PEAK PlasmaBlade are registered and/or trademarks of PEAK Surgical Inc. U.S. Patents No. 6,135,998, 6,913,605, 6,730,075, 6,780,178, $7,238,185$, and 7,357,802.) was used in 24 operations, and electrocautery (Olympus EUS 10; Kyoritsu Electric Co., Shizuoka, Japan) was used in 22 operations in random order to manage skin flaps and excise breast tissue along with the underlying pectoralis fascia. Patients with locally advanced breast cancer who were undergoing neoadjuvant chemotherapy, and patients who had undergone simple mastectomy were excluded. Age, body mass index $\left(\mathrm{BMI}, \mathrm{kg} / \mathrm{m}^{2}\right)$, breast volume 
(mastectomy specimens were directly put into a graduated cylinder before fixation and the volumes were determined by the water displacement method), concomitant disorders, tumour stage, number of dissected lymph nodes, flap area (length of the flap multiplied by width in $\mathrm{cm}$ ), operation duration (the time from starting skin incision to the time of suturing the skin), and blood loss amount (measured by the number of sponges used and sponge weight) of the patients were recorded. In the postoperative period, vacuum drainage amount and duration as well as the time of starting arm exercises were also recorded. Complications such as seroma, surgical site infection (SSI), hematoma and flap necrosis were determined. Fluid that collected under the skin flaps and axilla that presented clinical findings and which required multiple aspirations were accepted as seroma. The presence of erythema, purulent drainage, localized heat increase, cellulitis, pain, redness, sensitivity, and related wound dehiscence were regarded as SSI. The collections observed in operation fields with skin colour changes and mass effect were accepted as hematoma.

\section{Surgical technique}

After a skin incision was made with a scalpel, the skin flaps were lifted up with the help of hooks. In the plasmacautery group, skin incision was also made with plasmacautery. Flaps were prepared with plasmacautery in the plasmacautery group (Figure 1) and with electrocautery in the electrocautery group. Only large vessels such as perforating branches of the arteria mammaria interna were tied with $3 / 0$ silk, while other bleeding vessels were sealed with plasmacautery and electrocautery. Plasmacautery and electrocautery were also used for pectoralis fascia and breast tissue removal in their own groups. Axillary dissection of all patients was performed with scalpel.

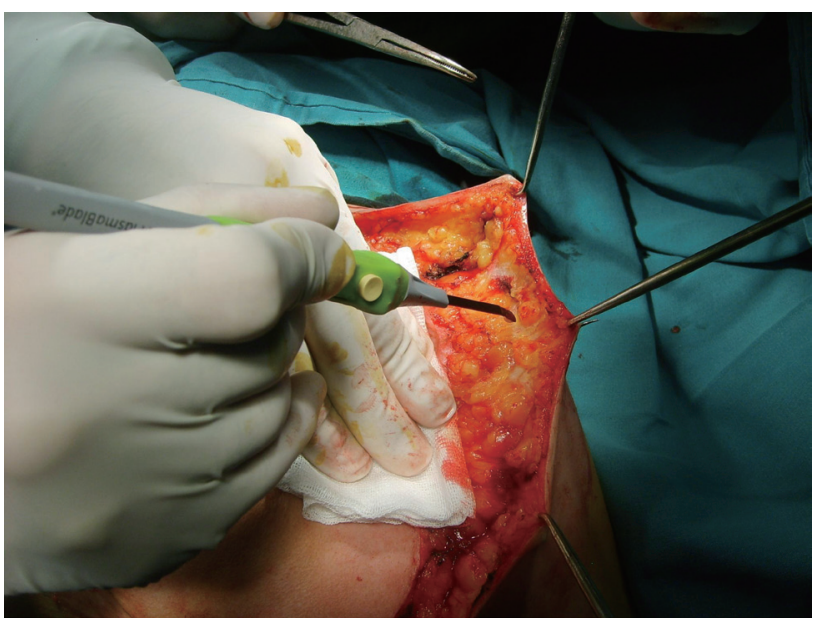

Figure 1. Preparing upper flaps with plasmacautery in mastectomy.
Electrocautery was used in both the coagulation and cutting modes in the 20 to $30 \mathrm{~V}$ range, and plasmacautery was used in the 6 to 8 numeric set point range in both the coagulation and cutting modes. The thoracodorsal pedicle and thoracicus longus nerves were preserved. Standard level 2 dissection was carried out in all patients. However, level III dissection was also performed in patients with macroscopic involvement during surgery. Closed suction drains were used in all patients after hemostasis. Subcutaneous tissue was approximated with absorbable sutures and the skin was closed with subcuticular continuous sutures. Daily drainage volume was recorded and the drains were not removed until the daily drainage decreased to less than $50 \mathrm{~mL}$. Prophylactic antibiotics were not used in any of the patients. All the operations were managed by surgical oncologists specializing in breast surgery.

\section{Statistical analyses}

SPSS version 10.0 (SPSS Inc., Chicago, USA) software was used to analyze the data. The differences between the groups were analyzed with the Mann-Whitney $U$ test, and the chisquare test was carried out for the comparison of the complications.

\section{RESULTS}

Age, BMI, breast volume, and flap area parameters were

Table 1. Patients and tumor characteristics

\begin{tabular}{lccc}
\hline Characteristic & $\begin{array}{c}\text { Plasmacautery } \\
\text { group }(\mathrm{n}=24)\end{array}$ & $\begin{array}{c}\text { Electrocautery } \\
\text { group }(\mathrm{n}=22)\end{array}$ & p-value \\
\hline Age $(\mathrm{yr})^{*}$ & $49.3 \pm 5.7$ & $51.6 \pm 6.1$ & $\mathrm{NS}$ \\
BMl $^{*}$ & $29.9 \pm 0.5$ & $28.2 \pm 0.4$ & $\mathrm{NS}$ \\
${\text { Tumor size }(\mathrm{cm}){ }^{\dagger}}_{\text {Involved lymph node status (\%) }}$ & $2.4(1.6-3.3)$ & $2.6(1.8-3.5)$ & $\mathrm{NS}$ \\
Flap area $\left(\mathrm{cm}^{2}\right)^{*}$ & 29.0 & 27.2 & $\mathrm{NS}$ \\
Breast volume $\left(\mathrm{cm}^{3}\right)^{*}$ & $1,090 \pm 217$ & $461 \pm 94$ & $\mathrm{NS}$ \\
\end{tabular}

$\mathrm{NS}=$ not significant; $\mathrm{BMl}=$ body mass index .

${ }^{*}$ Mean \pm SD; ${ }^{\dagger}$ Median (range)

Table 2. Comparative results of parameters

\begin{tabular}{|c|c|c|c|}
\hline & $\begin{array}{l}\text { Plasmacautery } \\
\text { group }(n=24)\end{array}$ & $\begin{array}{l}\text { Electrocautery } \\
\text { group }(n=22)\end{array}$ & $p$-value \\
\hline Duration of hospital stay (day) & $4.3(2-6)$ & $4.6(2-7)$ & NS \\
\hline Time to start arm exercises (day) & $8.1(5-10)$ & $7.8(4-11)$ & NS \\
\hline Drainage duration $(\text { day })^{*}$ & $5.5(3-7)$ & $7.9(5-12)$ & 0.020 \\
\hline Drainage volume $(\mathrm{mL})^{*}$ & $707(425-910)$ & $1093(700-1200)$ & 0.025 \\
\hline Operation duration $(\mathrm{min})^{\dagger}$ & $88 \pm 19$ & $94 \pm 23$ & NS \\
\hline Blood loss $(m L)^{\dagger}$ & $113 \pm 21$ & $122 \pm 32$ & NS \\
\hline $\begin{array}{l}\text { Morbidity (seroma, hematoma, } \\
\text { SSI, flap necrosis) (\%)* }\end{array}$ & 12.5 & 18 & NS \\
\hline
\end{tabular}

NS = not significant; $\mathrm{SSI}=$ surgical site infection .

${ }^{*}$ Median (range); ${ }^{\dagger}$ Mean \pm SD. 
similar in each group. Mean age of the patients was $50.4 \pm 6.8$ years; mean BMI was $29.1 \pm 0.7$, mean breast volume was $1,120 \pm 346 \mathrm{~cm}^{3}$, and mean flap area was $446 \pm 107 \mathrm{~cm}^{2}$ (Table 1). Median drainage duration was 5.5 days in the plasmacautery group and 7.9 days in the electrocautery group $(p=0.020)$. In the plasmacautery and electrocautery groups, median drainage volume was 707 and $1,093 \mathrm{~mL}$, respectively $(p=0.025)$. The median tumor size was $2.5 \mathrm{~cm}$ for the entire group. There was axillary metastasis in $28 \%$ of all patients. Median hospital stay was 4.3 days in the plasmacautery group and 4.6 days in the electrocautery group. Mean time to start arm exercises was 8.1 days for the plasmacautery group and 7.8 days for the other group. Mean operation duration was $88 \pm 19$ minutes in the plasmacautery group and $94 \pm 23 \mathrm{~min}$ utes in the electrocautery group. There was no statistical significance between the groups when operation duration, amount of blood loss, time to start arm exercises, seroma, hematoma, SSI, and flap necrosis were considered (Table 2). In the plasmacautery group, there were 2 seromas and 1 SSI, whereas in the electrocautery group there were 2 seromas, 1 hematoma, and 1 SSI in the early postoperative period.

\section{DISCUSSION}

Plasma is an electrically conductive cloud created when radiofrequency energy contacts tissue. It is comprised of water vapor and charged particles called ions (positive and negative charges) from the breakdown of the tissue. Plasmakinetic cautery is a new electrosurgical device that uses pulsed radiofrequency to generate a plasma-mediated discharge along the exposed rim of an insulated blade, creating an effective cutting edge while the blade stays near body temperature [1]. Based on innovative proprietary technology, the PEAK Surgery System is a tissue dissection system that represents an important advance in radiofrequency (RF) surgical technologies. It consists of the PEAK PlasmaBlade disposable cutting devices and the PULSAR Generator. PEAK PlasmaBlade devices offer the precision of a scalpel and the bleeding control of traditional electrosurgery without the usual extensive collateral tissue damage. The PULSAR Generator supplies pulsed plasma RF energy to the PEAK PlasmaBlade devices with an intuitive interface that is easy to use. The plasmakinetic cautery cuts at a much lower average temperature than that of conventional electrocautery, and can be as low as 50 degrees centigrade [2]. The generation of high-frequency currents (100 kHz to $4 \mathrm{MHz}$ ) which induces ionic vibration is the main working principle of standard bipolar electrocautery devices. Ionic vibration generates intracellular heat resulting in boiling and explosion (CUT), and/or dehydration (desiccation), and/ or fire (fulguration) resulting in coagulation.

Seroma is an accumulation of serous fluid that develops following the formation of skin flaps during mastectomy or in the axillary dead space in the acute postoperative period [3]. There has been no consistent definition of seroma in the literature, although it has been documented most frequently when it is symptomatic, bothersome to the patient and requires at least one needle aspiration [4]. The incidence of such occurences varies widely according to the type of surgical treatment and the operative techniques used, ranging from less than $10 \%$ to more than $50 \%$ [5]. Electrocautery is one named cause of seroma formation in the literature [6]. The seroma formation is the next step coming after prolonged drainage duration and increased drainage amount, however we couldn't establish the statistical difference between the groups because of the small sample size. The present study clearly showed that the drainage duration $(p=0.02)$ and the amount drained $(p=0.025)$ were low in the plasmakinetic cautery group. We were not able to find any statistical significance between the groups when SSI and flap necrosis were considered, most likely once again due to the small sample size. However, it has been suggested in the literature that wound complications such as cellulitis, infection, and necrosis increase with electrocautery $[7,8]$.

Prolonged drainage period diminishes patient comfort, causes a delay in the starting of arm exercises as well as discharge from hospital [9]. Although the drainage period was statistically significant in the plasmacautery group, this did not affect hospital stay and the starting of arm exercises. In our hospital there is no objection to discharging breast surgery patients with inserted hemovac drains. The patients in the electrocautery group spent much more time at home with their inserted drains than the patients in the other group. Furthermore, we did not witness a shorter drainage period before starting arm exercises in the electrocautery group because the physiotherapy unit in our hospital recommends a minimum waiting period of seven days after surgery to start arm exercises.

Subjectively, tissue dissected with the PlasmaBlade retained a healthy appearance with none of the charring or obvious damage typically seen with traditional electrosurgical technology. From a technical standpoint, dissection with the PlasmaBlade was facile, requiring less pressure than a scalpel, yet retaining a tactile feel for the tissue plane. Working in wet liquefied fat and dry fields required no technical changes or additional suction, and this allowed the dissection to continue unimpaired. Additionally, there was significant risk reduction due to the elimination of sharp instrument use $[10,11]$.

There are very few studies in the literature investigating 
plasmakinetic cautery and most of the ones that exist are experimental studies. As far as we know, this is the first study comparing electrocautery and plasmakinetic cautery in modified radical mastectomy. Therefore, we were not able to compare our study with other studies. Plasmakinetic cautery is a promising new surgical instrument that provides atraumatic, scalpel-like cutting precision and electrosurgical-like hemostasis, resulting in minimal tissue injury. Without prolongation of operation duration or an increase in the amount of blood loss, plasmacautery shortens the drainage amount and duration compared to electrocautery. Devitalization of tissue and lysis of subcutaneous fatty tissue results from the application of high thermal energy and electrocautery may explain these advantages. Plasmakinetic cautery seems to have advantages in reducing both the drainage period and total drainage volume compared to electrocautery. This study is important because it sheds light on the advantages of plasmakinetic cautery over electrocautery despite the small sample size. Future randomized controlled studies on plasmakinetic cautery with large sample sizes are needed to show more clearly the advantages of plasmakinetic cautery. The tissue damage involved in plasmakinetic cautery should be explained in terms of cytokines and biochemical parameters in order to gain wider acceptance of its use in breast surgery.

\section{CONFLICT OF INTEREST}

The authors declare that they have no competing interests.

\section{REFERENCES}

1. Loh SA, Carlson GA, Chang EI, Huang E, Palanker D, Gurtner GC. Comparative healing of surgical incisions created by the PEAK Plasma-
Blade, conventional electrosurgery, and a scalpel. Plast Reconstr Surg 2009;124:1849-59.

2. Ruidiaz ME, Messmer D, Atmodjo DY, Vose JG, Huang EJ, Kummel AC, et al. Comparative healing of human cutaneous surgical incisions created by the PEAK PlasmaBlade, conventional electrosurgery, and a standard scalpel. Plast Reconstr Surg 2011;128:104-11.

3. Pogson CJ, Adwani A, Ebbs SR. Seroma following breast cancer surgery. Eur J Surg Oncol 2003;29:711-7.

4. Kuroi K, Shimozuma K, Taguchi T, Imai H, Yamashiro H, Ohsumi S, et al. Pathophysiology of seroma in breast cancer. Breast Cancer 2005;12: 288-93.

5. Lumachi F, Brandes AA, Burelli P, Basso SM, lacobone M, Ermani M. Seroma prevention following axillary dissection in patients with breast cancer by using ultrasound scissors: a prospective clinical study. Eur J Surg Oncol 2004;30:526-30.

6. Yilmaz KB, Dogan L, Nalbant H, Akinci M, Karaman N, Ozaslan C, et al. Comparing scalpel, electrocautery and ultrasonic dissector effects: the impact on wound complications and pro-inflammatory cytokine levels in wound fluid from mastectomy patients. J Breast Cancer 2011; 14:58-63.

7. Miller E, Paull DE, Morrissey K, Cortese A, Nowak E. Scalpel versus electrocautery in modified radical mastectomy. Am Surg 1988;54:284-6.

8. Hoefer RA Jr, DuBois JJ, Ostrow LB, Silver LF. Wound complications following modified radical mastectomy: an analysis of perioperative factors. J Am Osteopath Assoc 1990;90:47-53.

9. Stevens WG, Gear AJ, Stoker DA, Hirsch EM, Cohen R, Spring M, et al. Outpatient reduction mammaplasty: an eleven-year experience. Aesthet Surg J 2008;28:171-9.

10. Ruidiaz ME, Martin DT, Ta CN, Vose JG, Cortes-Mateos MJ, WangRodriguez J, et al. A prospective controlled trial of the PEAK PlasmaBlade in the evaluation of breast cancer surgical specimens with touch prep. The 11th Annual Meeting of American Society of Breast Surgeons. 2010. Abstract \#206.

11. Sangoi A, Vose J, Atmodjo D, Naruns P. A randomized controlled trial of the PEAK PlasmaBlade in open breast biopsy compared to scalpel and traditional electrosurgery. The 11th Annual Meeting of American Society of Breast Surgeons. 2010. Abstract \#209. 